keeping meant different things to different clinicians. Explicit documentation criteria make communication clearer for follow-up as well as risk management. Taking into account the World Health Organization (WHO) eligibility criteria, ${ }^{2}$ the Cochrane Database, ${ }^{3}$ the Royal College of Obstetricians and Gynaecologists (RCOG) recommendations ${ }^{4}$ and known frequency and seriousness of complications ${ }^{5}$ we agreed a standard of documentation for an IUD insertion in our service. A balance needed to be struck between recording sufficient information to adequately reflect the consultation but not so much that it was unmanageable. The agreed documentation included three main areas - pre-insertion, procedure and postinsertion - see Table 1 .

The agreed recommendations for standards of documentation were incorporated into the IUD clinical protocols and distributed to all clinicians in the service. The individual, confidential comparative feedback allowed staff to reflect on their strengths and areas for improvement in a non-threatening manner. We plan to reaudit to ensure standards are being maintained.

\section{Conclusion}

This audit clarifies what we should do, why we should do it, and how we should record it to enhance communication and reduce risk. We were able to agree a minimum standard for practice to enhance adequate counselling, safe insertion, communication with colleagues and risk management.

\author{
Acknowledgements \\ The authors would like to thank the members of the audit team who helped \\ to formulate the standards and all the staff who wholeheartedly took on \\ board the feedback. \\ Statements on funding and competing interests \\ Funding. None declared. \\ Competing interests. None declared. \\ References \\ Goodwin H. Family planning - medico legal trends. Journal of the MDU 2000; 16: 23-24. \\ World Health Organization (WHO). Improving access to quality care in family planning: \\ medical eligibility criteria for contraceptive use (2nd edn). Geneva: WHO, 2001. \\ medical eligibility criteria for contraceptive use (2nd edn). Geneva: WHO, 2001.
Grimes DA, Schulz KF. Antibiotic prophylaxis for IUD insertion. Cochrane Database Syst Rev \\ Grimes D A, \\ $1999 ; 4$ \\ Royal College of Obstetricians and Gynaecologists (RCOG). Recommendations arising from \\ the 31 st Study Group: the prevention of pelvic infection. In: Templeton A (ed.), The prevention \\ of pelvic infection. London: RCOG Press, 1996; 267-270. \\ Gupta S, Kirkman R. Intrauterine devices - update on clinical performance. The Obstetrician \& \\ Gynaecologist 2002; 4: 37-43.
}

\title{
Revisiting 'Fraser ruling competence' for under 16s in the UK
}

\author{
Gillian Vanhegan, DRCOG, MFFP, Brook Medical Spokesperson, Brook, London, UK
}

Correspondence: Gillian Vanhegan, Brook Medical Spokesperson, Brook, 421 Highgate Studios, 53-79 Highgate Road, London NW5 1TL, UK. www.brookcentres.org.uk

(Accepted 24th May 2002)

\section{The Journal of Family Planning and Reproductive Health Care 2002: 28(3): 158}

One-quarter of women and nearly one-third of men have sex under the age of 16 years but the average age at first sexual intercourse is 16 for both sexes, according to the recent National Survey of Sexual Attitudes and Lifestyles. ${ }^{1}$ Two in five men and four in five women in their late teens and early twenties who first had sex at the age of 13 and 14 wished they had waited longer, so there is no doubt that young people under the age of 16 need to be able to discuss sexual matters with a health professional. They will be given accurate information, which helps them to make informed choices as to when they start sexual activity and how to lead a healthy sexual lifestyle.

The Sexual Health Research Unit at the University of Southampton recently found that over $50 \%$ of boys get their information from television and magazines; one-third of the young men said that they would like more information from doctors (R Ingham, personal communication, 2001). Young women also rated magazines highly as a source of information, but $40 \%$ said that they also saw the doctor or nurse as a source of information. Young people, especially those aged under 16, still have reservations about approaching general practitioners (GPs) and family planning clinics for advice about contraception, although it is 16 years since the case of whether or not doctors could advise and prescribe for under 16-year-olds without parental consent or knowledge. A test case $^{2}$ went through the legal system and ultimately to appeal in the House of Lords. The final ruling was made by Lord Fraser, who stated that the doctor should always encourage the young person to share their need for contraception with a parent or allow the doctor to do so. If the young person explained to the doctor it was not desirable or possible to discuss these matters at home, given the family relationships or circumstances, then the doctor takes on the responsibility for helping the young person without parental consent.
The doctor needs to discuss the sexual relationship or proposed relationship with the young person to help the young person to decide whether they are comfortable and are in no way being pressurised or abused. The young woman is asked if she intends to continue her present relationship and the doctor assesses her need for contraception and whether her physical or mental health would be damaged by lack of advice or prescription. When the decision is made to prescribe for the young person the doctor must feel confident that the patient is mature enough to understand the decision she is making. The doctor should explain the method in detail and allow the young person to ask any questions.

The decision is then made by the doctor whether it is in the best interests of the under 16-year-old to prescribe for her in order to protect her against unintended pregnancy or sexually transmitted infections (STIs). Previously the assessment of the young person's maturity was called 'Gillick competence'; the current terminology is 'Fraser ruling competence', after Lord Fraser who was one of the Law Lords who ruled in the test case.

GP practices and community clinics should put in their practice/clinic leaflets, and any other relevant information materials, that they offer a confidential service for those under 16. It is particularly important to display this information in reception areas, so that young people are made aware of this. This should encourage more young people to consult doctors and nurses, so that they can be given accurate information on sexual health in an open and non-judgmental way.

\footnotetext{
Statements on funding and competing interests Funding. None declared.

Competing interests. The author is the Medical Spokesperson for Brook. References

Wellings $\mathrm{K}$, Wadsworth J, Field J, et al. National survey of sexual attitudes and lifestyles.

Gillick v Wisbech and West Norfolk AHA (1985), 3 A11 ER 402 HL.
} 